\title{
ORALIDAD EN LA NOVELA FRÍVOLA DE CORÍN TELLADO / ORALIDAD EN LA NOVELA FRÍVOLA DE CORÍN TELLADO*
}

\author{
Francisco Javier GIL JACINTO \\ Universidad de Sevilla
}

\section{RESUMEN}

La intención de este trabajo es analizar los rasgos de oralidad en los diálogos de los personajes de la novela Frívola (1958), de la autora de literatura rosa Corín Tellado. Con el fin de no desviarnos del objetivo inicial, se ha dejado fuera de consideración el debate sobre la valoración, generalmente negativa, que la crítica especializada ha hecho de este tipo de producciones. De este modo, partiendo de una definición amplia de literatura, como la provista por Culler (2000), hemos podido abordar la investigación de Frívola con los mismos parámetros de análisis que los aplicados en otras investigaciones llevadas a cabo con obras canónicas.

Palabras Clave: oralidad, escrituralidad, habla coloquial, Corín Tellado, novela rosa.

\section{AbSTRACT}

The intention of this work is to analyse the oral features in the dialogues of the characters in the novel Frivola (1958) by the author of romantic literature Corín Tellado. In order not to deviate from the initial objective, the debate about literary value, generally negative, that criticism has made of this type of productions, is outside the scope of this essay. Starting from a broad definition of literary work, such as that provided by Culler (2000), we have been able to research Frivola with the same parameters of analysis as those applied to the work of other authors.

KEYWORDS: orality, scripturality, colloquial speech, Corin Tellado, romantic novel.

Fecha de recepción: 01/04/2018

Fecha de aceptación: 19/05/2018

Fecha de la versión definitiva: 10/06/2018

\footnotetext{
* Al profesor Antonio Narbona, cuyas clases magistrales inspiraron este trabajo.
} 


\section{El Difícil ENCAJE DE LO COLOQUiAL EN LA LITERATURA}

Dentro del amplio campo de la investigación filológica, un área de estudio en la que se viene observando una feliz confluencia de la Lingüística y la Literatura es aquella que se ha ocupado de indagar acerca de las relaciones entre la oralidad y la escrituralidad. De ello dan fe una serie de trabajos centrados en el análisis de la recreación de lo oral y lo coloquial en obras literarias de renombre, como las de Sacido Romero (1995), Viñao Frago (2004), Castaño Restrepo (2007), López Serena (2007) e Illades Aguiar (2014), solo por citar algunas.

Todos los textos citados anteriormente forman parte del canon consagrado de la literatura en lengua castellana, e incluso algunos de ellos, de su producción áurea, pero, tal y como plantea Illades Aguiar (2014), son muchos los estudiosos que, al analizar la oralidad en la producción literaria del Siglo de Oro español, identifican esta, sin definirla, con la mímesis oral y la literatura efímera. La vinculación de este tipo de producciones de masas con lo oral, frente a lo escritural, sin haber llegado a realizar un verdadero estudio de las técnicas narrativas empleadas por sus autores, se relaciona, no cabe duda, con la falta de interés que, según Fernando Eguidazu (2008: 115-116), ha venido despertando la novela popular española, donde toda la atención se ha dirigido a la llamada novela culta y a descubrir la esencia del lenguaje literario, que en este tipo de literatura parece no existir. En este mismo sentido, Andreu (2010: 37) piensa que «la carencia de estos estudios se debe a la opinión negativa que se tiene especialmente entre la crítica del texto popular, al que críticos como Díez Echarri, Roca Franquesa o Valbuena Prat han denominado siempre con términos peyorativos».

El resultado de este tipo de consideraciones parece haber sido que, de manera casi instintiva, se haya venido asociando la lengua en su registro coloquial, incluso cuando es usada dentro de la propia literatura, como desprovista de calidad artística al compararla con la variedad escrita. De ahí, por ejemplo, la supuesta vulgaridad y pobreza de estilo de Pérez Galdós, o Don Benito el Garbancero, a pesar del intento de Sánchez Barbudo (1956) de acabar con esa visión negativa del casticismo galdosiano.

Con el fin de no perdernos en disquisiciones acerca de los límites entre la alta y la baja literatura, ni desviarnos del objetivo último de este trabajo, partiremos de un concepto amplio del término tomado de Jonathan Culler:

En la mayoría de los casos, lo que como lectores nos impulsa a tratar algo como literario es, sencillamente, que lo encontramos en un contexto que lo identifica como tal, en un libro de poemas, en el apartado de una revista, o en el anaquel de librerías o bibliotecas (2000: 39). 


\section{LA CONSIDERACIÓN DE TEXTO LITERARIO DE UNA NOVELA ROSA DE CoRín Tellado a LA LUZ de la DEFINición DE Culler}

El amplio marco conceptual de literatura proporcionado por Culler nos permite afirmar que, en tanto que, de acuerdo con el catálogo REBIUN ${ }^{1}$, existen algunos ejemplares de Frívola (1958) en los fondos bibliotecarios de las universidades de Oviedo, Complutense de Madrid, Las Palmas de Gran Canarias y en la sala de lectura del Instituto Cervantes de Burdeos, dicha publicación se trataría, efectivamente, de una obra literaria. Pero la evidencia palpable de ello, al menos para el autor de este trabajo, y en la cual se encuentra el origen de su elección como objeto de estudio, fue el hallazgo de un ejemplar de Frívola en la sección de literatura de una biblioteca pública de Sevilla, donde se hallaba situado entre Amapola de Tejera Osuna (2012), una novela producto del culebrón televisivo Amar en tiempos revueltos, y Nada de Teller (2011), un premio al mejor libro del año 2011 del Ministerio de Cultura de Dinamarca.

Otro hecho que acrecentó este interés espontáneo y personal por esta novela de Corín Tellado fue comprobar que, en una ciudad de reconocida tradición literaria como Sevilla, de las casi cinco mil novelas firmadas por la autora, únicamente Frívola y otra titulada Angustiosa esclavitud (1983), disponible en la Biblioteca Pública Provincial de Sevilla, merecieran pasar el filtro del reconocimiento literario que, según Culler, confiere el hecho de encontrarse en el anaquel de una biblioteca ${ }^{2}$. Pero tanto o más sorprendente que la presencia de estos dos títulos en concreto, y que explican mi decisión de centrar mi trabajo en uno de ellos, lo es la ausencia de otros, porque, tal y como recuerda Carmona González citando a Cabrera Infante,

Corín Tellado vende mucho más que Miguel de Cervantes. Sus obras se leen en sitios donde jamás se ha oído hablar de Cervantes. Esto se dice pronto, pero es verdad. Lo que demuestra que la novela rosa es un género que ha estado vivo durante siglos, que no es un fenómeno reciente (Carmona González 2009: 225).

\section{ANÁliSis DE LA ORALIDAD EN FRÍVOLA ATENDIENDO EXCLUSIVAMENTE} A SU CONDICIÓN DE OBRA LITERARIA

Una vez aceptada, al menos en el sentido amplio que provee Jonathan Culler, la consideración de Frívola como objeto literario, el presente estu-

${ }^{1}$ La Red de Bibliotecas Universitarias Españolas. <http://www.rebiun.org/queesrebiun/ Paginas/default.aspx $>$.

${ }^{2}$ Este dato ha sido extraído del catálogo en línea de la Red de Bibliotecas Públicas de Andalucía. <https://www.juntadeandalucia.es/cultura/absys/abnopac/abnetcl.cgi/O22064/ IDdb27a774/NT1>. 
dio no debería diferir sustancialmente del llevado a cabo con otras obras más celebradas, por muy tentador que resulte establecer paralelismos con otros productos de consumo populares a los que se ha ampliado el debate acerca de los rasgos de oralidad y escrituralidad presentes en los mismos, como son los llamados talk shows televisivos (Danilova 2008), las comedias de situación (Matamala 2008), los guiones de telenovelas (Pardo 1994), la prensa escrita (Rueda 2008) o el cómic (Naro 2008).

Así pues, el tipo de análisis que se pretende aplicar aquí es el que propone López Serena (2007) cuando sostiene que es preciso indagar en lo oral y lo escrito de manera conjunta, examinando las similitudes y las diferencias entre las producciones de una y otra clase, pero sin mantener actitudes favorables para las escritas y desfavorables para las orales, las cuales han venido siendo calificadas «de imperfectas, inacabadas, inconsistentes, imprecisas y abundantes en incorreciones en comparación con la ejemplaridad de los textos escritos, canonizados por una práctica secular de análisis filológico» (2007: 80). Dicha práctica parece, en cambio, haber dado poca importancia a la necesidad de una caracterización de la sintaxis coloquial defendida por Narbona Jiménez (2015: 126-134; 1989b: 149-169), quien señala que los rasgos utilizados para su delimitación, a los que nos referiremos más adelante, como son la presencia de elipsis, rupturas, repeticiones, dobles sentidos, expresiones de relleno, frases inacabadas, uso de deícticos, dominio de la afectividad, simplicidad, parataxis, etc., han terminado identificándose sin más con un intento fallido de gramática.

\subsection{El uso del diálogo como técnica narrativa: interrumpir, atajar, desviarse, rectificar y volver a empezar}

Lo primero que llama la atención de la composición formal de los ocho capítulos de la novela en los que tienen lugar los juegos de seducción de los protagonistas es la abundancia de diálogos. Solo por ello, podríamos afirmar ya que nos encontramos ante una situación prototípica del discurso oral, caracterizada por Casamiglia y Tusón (2002: 21) como aquella en la que se da la participación simultánea de dos interlocutores en un contexto determinado. Ahora bien, Narbona Jiménez (2015: 255) señala que, para poder llevar a cabo con fidelidad el trasvase del coloquio espontáneo a la literatura, hay que proporcionarle al lector el contexto, lo que lo convierte en un coloquio literario. En todo caso, uno de los rasgos definitorios de los intercambios orales, del tipo que sean, es su naturaleza plurigestionada, que da lugar a colaboraciones, rectificaciones e interrupciones, entorpeciendo o favoreciendo el avance, como ocurre en los diálogos siguientes: 
-Déjame.

-Ahora no puedo, Rita. Me has...

-¿Lastimado?

-Embrujado.

-Eres maravillosa, Rita -dijo él torpemente-. A veces siento infinitos deseos de robarte y de llevarte a un lugar donde solo estuviéramos los dos. Otras...

-Otras me odias ¿verdad? (134)

-Eres una mujer de hielo, muchacha.

-Lo prefiero así.

-No obstante, aquel día...

-Aquella noche, Smith -atajó Rita bruscamente. (51)

Un elemento de la oralidad relacionado con las interrupciones es el solapamiento de las frases de los interlocutores, de manera que uno puede terminar la que ha comenzado el otro y cambiar la intención de esta:

-Deja a mi padre. Él es...

-Un egoísta. Sabía que yo te amaba. Se lo había dicho aquella misma noche. ¿Por qué después te separó de mí? (134)

Otros rasgos atribuidos a la sintaxis oral, y presentes en Frívola, son las reformulaciones, los cortes en la exposición de una idea, las desviaciones y las frases inacabadas relacionadas con el curso libre del pensamiento:

-Ignorabas que la mujer con la que se va a casar Ray Peck es... su secretaria.

-No -dijo con un hilo de voz- su secretaria es una mujer bella, pobre... Se casará con él por dinero. Yo no podré...

-Pero ¿por qué? ¿Por qué se ha vuelto un golfo, si antes era un perfecto caballero?

-Eso no lo sabe nadie, Rita. Yo creí... todos creíamos... que tú...

\subsection{Las dificultades para representar la oralidad en la lengua escrita y la necesidad de un autor atento para completar lo no dicho explícitamente por sus protagonistas}

Además de los elementos sintácticos y semánticos, en cualquier conversación hablada hay que contar con los cinéticos y proxémicos entre los participantes que intervienen en ella, o, para expresarlo de una manera más simple, como hace Fernando Poyatos (2004: 116), «cuando uno habla se explican y se amplían cosas que por escrito luego no aparecen», y esto es algo que los autores de novelas necesitan reflejar de alguna manera. Es de- 
cir, en la representación escrita de la oralidad, se hace precisa a veces la intervención del narrador, o de otro modo se perdería el sentido literal del diálogo, como se observa muy bien en el siguiente:

-Escuche, Ray; tanto mi padre como usted están obcecados. Tengo conocimiento de lo que sucedió hace muchos años y puedo jurarle que mi padre no fue culpable de nada. Usted nunca le pidió una explicación y, como es natural, Joe Smith no se la dio. Por otra parte, usted...

-Siga, siga, todo lo que dice es muy interesante -sonrió el señor Peck, burlonamente $^{3}$. (94)

Aquí, el lector, sin el añadido de la autora, hubiera hecho una interpretación muy diferente, ya que la ironía o la burla, por lo general fáciles de percibir en una situación de oralidad, no lo son de igual modo en la lengua escrita, por lo que hay que recurrir a ciertas ayudas de tipo estilístico. La elaboración de la situación contextual, innecesaria en la lengua oral, forma parte de los artificios de creación literaria, y están muy presentes en la novela de Corín Tellado. Son frecuentes las frases de personajes en las que, de eliminarse tales ayudas a los lectores, estos tendrían serios problemas para interpretarlas correctamente. Analicemos algunas de ellas:

-¡Ah! -exclamó divertida-, ¿de modo que la hermana de ese hombre fue tu antiguo amor? (21)

-Papá -dijo, con fuerza y acento vibrante-, me han dicho que te vas a casar. (86)

Con respecto a la primera intervención, es muy probable que el lector se halle inclinado a pensar que quien la pronuncia esté sorprendido, o incluso molesto, antes que divertido, mientras que en el segundo ejemplo tendería a interpretar que quien la formula se siente contrariado, pero ello sería debido más a una idea preconcebida acerca de las segundas nupcias de los padres que al sentido literal del texto escrito.

A la dificultad para representar la oralidad en la escritura, hay que sumar otra más, y es el hecho de que los diálogos ocurren en un espacio y un tiempo compartidos por quienes intervienen en ellos, a los cuales, en una situación de habla real, no es necesario referirse de manera explícita, pero sí lo es en la ficción literaria para que el lector pueda estar al tanto de dichas circunstancias e interpretar el contenido de los diálogos adecuadamente. Lo mismo ocurre con el conocimiento directo de ciertos objetos, personas o conceptos, a los que, sin el concurso de la autora de la novela, solo tendrían acceso los protagonistas; de ahí que Corín Tellado sea muy cuidadosa en cuanto al uso de hiperónimos y deícticos para nombrarlos.

${ }^{3}$ Los subrayados que aparecen a partir de ahora no pertenecen a la novela. 
Ese principio es observado en el texto, por ejemplo, en una situación donde una carta va a ser determinante para el desarrollo de los acontecimientos. En ella, el término carta se menciona cuando aparece por primera vez, tanto para los lectores, como para alguno de los protagonistas, pero luego ya no es necesario hacerlo. De igual modo, tampoco lo es repetir una acción ya mencionada o usar el nombre de pila si los que intervienen en la conversación conocen a la persona de quien están hablando:

- ¿Y la carta, Tom?

-¿Qué carta, prenda mía?

-La que me entregó la señorita.

-¡Ah, eso tú sabrás!

Escudriñó en todos los bolsillos. De súbito, Tom miró hacía el suelo y dijo: - ¿Será ésa, Nati?

Nati recogió aquel sobre y lo apretó nerviosamente.

-¡Qué susto me he llevado! Sí, es ésta... (107)

Por lo general, las deixis exofóricas, abundantísimas en los intercambios orales cotidianos, son, sin embargo, muy poco frecuentes en Frívola, al contrario de lo que ocurre con el uso de los nombres propios, omitidos o sustituidos en la vida real, pero recurrentes a lo largo de la novela:

- ¿Quién ha traído eso, Nati?

-Un botones. (149)

En este caso, el lector sabe que eso es un «gran ramo de flores y una carta» porque lo ha leído justo una línea más arriba, y que Nati es la persona aludida. Pero lo habitual en esta novela es que este tipo de deícticos, cuando aparecen, incluyan una aclaración por parte del mismo que formula la frase, algo que por lo general no ocurre en una situación de oralidad, a menos que se quiera causar algún efecto en quien está escuchando, y lo mismo ocurre con el uso del vocativo. De ello se deduce que este tipo de información se le ofrece al lector más que al oyente, como ocurre en un pasaje de la novela en el que dos personajes abandonan el salón de un club y uno dice:

-Puedes decir lo que quieras, aquí, en la terraza. Tengo el auto en la acera y a las nueve y media he de estar de regreso en casa. (124)

Ahora bien, es difícil saber hasta qué punto ese «en la terraza» ha sido planificado con tal fin o se trata de un caso de redundancia propio de la lengua coloquial. Lo mismo cabe decir de los datos relativos al tiempo en el siguiente ejemplo, puesto que no añaden información relevante y en una conversación oral, guiada por el principio de economía, quizás no se hubieran mencionado: 
-¿Qué tienes, Rita? Te estoy observando toda la tarde y te veo menos animada que cuando has llegado.

-Estoy perfectamente, papá. Son las ocho y voy a salir un momento. Quedé en verme con James en el club. (122)

\subsection{El paso de lo coloquial a lo literario y la pervivencia de la oralidad en los llamados nexos débiles}

Resulta lógico pensar que las referencias al paso del tiempo en las citas anteriores se relacionarían más con la necesidad de enmarcar el desarrollo de la acción que con la de aportar algún dato importante para los intervinientes, pero, en ese caso, se habría producido el salto del ámbito de lo oral a lo literario, algo que no siempre es fácil de discernir, como se verá en este extracto de la novela:

-Ya, eres una muchacha muy inteligente. Y otra cosa, Rita. El otro día te encontré repartiendo limosnas en un barrio humilde. Tu figura vivaracha, pero vestida sencillamente, adulteraba un tanto el ambiente de aquellas gentes. Vi en tus ojos algo... algo que no creí que tuvieras. Me pareció que tu alma se asomaba a la niña menuda de tus ojos glaucos... Más tarde, al llegar a casa encontré en mi mesa de trabajo una gran tarjeta; era para un baile que se celebraba al día siguiente en casa de unos amigos, con motivo del cumpleaños de su hija... No fui por divertirme -añadió desdeñoso-; francamente, las diversiones no me entusiasman, porque puedo jurar que jamás me he divertido en esa clase de fiestas. Fui también por simple curiosidad. Deseaba saber si había ido también Rita Peck... (76)

En el diálogo de más arriba se descubren inmediatamente características propias del lenguaje literario, como el hecho de presentar una cierta extensión, el uso de un lenguaje figurado y de una adjetivación abundante, junto con el empleo de unos términos más o menos poéticos o desusados, todo lo cual supone una cierta planificación frente a la espontaneidad, brevedad y concisión de la lengua hablada. Sin embargo, la literatura no puede reducirse a una serie de palabras pretendidamente poéticas, de la misma manera que la oralidad no puede confundirse con el uso de un vocabulario más corriente. Además, no solo en el universo fantástico de las novelas rosa, sino en una situación real de rapto amoroso, un amante puede permitirse intercalar en su prédica las voces glauco, alma y desdeñoso sin que suenen fuera de registro.

Por otra parte, en este texto al que nos venimos refiriendo aparecen también ciertos elementos típicos de la oralidad, como son las repeticiones, las frases inacabadas y la presencia de una serie de expresiones con función de conectores, tales como ya, y otra cosa, más tarde, francamente, puedo jurar que, los cuales formarían parte de ese grupo de los que Narbona 
Jiménez (1989: 81-82) opina que son difíciles de encajar en la categoría de la coordinación o de la subordinación, y que precisamente por su valor conectivo débil o vago se convierten en meros soportes conversacionales carentes casi de significado, pero que, sin embargo, intervienen constantemente para estructurar el lenguaje coloquial.

De acuerdo con Pérez Álvarez (2010: 109), este tipo de nexos, que sirven para establecer una relación semántica entre sintagmas en la lengua oral, tienden a perder su relación gramatical y reflejan el proceso acumulativo que sigue al trasvase de la información, menos planificado que en la escritura, donde, al contar con la posibilidad de revisión, permiten reordenar los sintagmas y las conexiones entre ellos. Encontramos construcciones como:

-Tú sabes -insistió Smith- que mis ojos te pidieron el clavel.

-No vuelvas a recordármelo. Además, te ruego que no sigas molestándome y no quiero complicaciones. (62)

-Ponte un abrigo encima, y vete en seguida, que ya es muy tarde. (106)

\subsection{La representación de las pausas del discurso oral y las marcas gramaticales en el texto escrito}

La necesidad de reorganizar el discurso sobre la marcha hace que vayan surgiendo una serie de paradas y arranques ausentes en los textos escritos planificados de antemano, donde la forma de señalarlos es mediante puntos y comas. Sin embargo, Pérez Álvarez (2010: 106-107) sostiene que las transcripciones de materiales grabados demuestran que las pausas, asociadas a dichas marcas gramaticales, solo se corresponden a las de las lecturas realizadas en voz alta, pero no a las del habla, donde los altos en el discurso se deben al cambio de unidades temáticas y no a criterios gramaticales, sino semánticos. Es posible entonces que, en ciertos casos, la utilización de puntos suspensivos en los diálogos de Frívola responda a un deseo de su autora de recoger este rasgo de oralidad que precede a la transición de un asunto a otro:

-Rita, yo te quiero mucho, como tú sabes. Después de morir tu madre, cifré en ti todas mis ilusiones... Cuando supe que amabas a Smith... (163)

3.5 Relaciones entre oralidad, modalidad de habla y clase social de los personajes de la novela

Con respecto a ciertos elementos fónicos y léxicos que, de acuerdo con Casamiglia y Tusón (2002: 56-61), caracterizan los intercambios orales, no 
se observa ningún intento por parte de Corín Tellado de plasmar la modalidad de habla de ningún grupo lingüístico, pero eso mismo, según Narbona Jiménez (2015: 267), ocurre en El Quijote, donde «casi ningún fenómeno marca sociolingüísticamente a unos personajes frente a otros». Otro rasgo de oralidad ausente en Frívola es el uso de abreviaciones, aumentativos o diminutivos; en cambio, son frecuentes las repeticiones léxicas o conceptuales, y especialmente abundantes son las relativas a las emociones, aunque ello dé lugar a un tipo de diálogos improbables en el habla, como ocurre en el caso siguiente sostenido entre un padre y una hija:

-Papá, amo a un hombre con toda mi alma, sé que podría ser infinitamente feliz a su lado. Él está dispuesto a todo por casarse conmigo, y sin embargo... Yo te ofrezco mi felicidad por tu felicidad, papá. Renunciaré al hombre que odias con toda tu alma.

-Entonces, Rita, ¿confiesas que amas a Joe Smith?

\subsection{El reflejo de la oralidad en la sintaxis de los diálogos de los personajes}

Por lo dicho hasta ahora, no parece que los rasgos del lenguaje oral haya que buscarlos en el léxico, sino en la sintaxis, para lo cual Narbona Jiménez (1989: 42) aboga por una mejor caracterización de lo coloquial y la superación de dicotomías como la de coordinación/subordinación que permita abordar, por ejemplo, el alcance de la utilización de la copulativa $y$ en el lenguaje oral frente a otro tipo de nexo subordinante «más complejo» atribuido a la escritura en frases como:

-Algún día me darás tu corazón y yo lo despreciaré.

En este ejemplo, la conjunción copulativa podría haber sido sustituida por las adversativas pero o aunque, convirtiendo la oración en subordinada sin que modificara el sentido general del enunciado. Sin embargo, de haberse realizado dicho cambio, la fuerza de la afirmación no habría sido la misma, puesto que su carácter sentencioso descansa en buena parte en la unión de dos acciones contrapuestas, la de dar y la de rechazar. Lo mismo ocurre con los verbos creer y equivocarse unidos mediante y en:

-... Creyó que mi amor por ti era una broma, y se equivocó.

Otra de las características de la sintaxis coloquial señalada por Narbona (1989: 83) es que su «gran vinculación a la situación hace innecesario que se verbalice todo lo que es fácilmente recuperable por el oyente». Esto permitiría al hablante prescindir de ciertos conceptos previos de la gramática tradicional y pronunciar frases que pueden interpretarse de manera com- 
pleta gracias a la información manejada por el oyente, ya sea de tipo general o de datos aportados recientemente, como en:

-Me has querido. Dicen que donde hubo cenizas...

${ }_{-¡ N o}$ me toques, Joe! ¡Soy capaz de...!

El fenómeno de las sentencias inacabadas, frecuente en las comparaciones, aparece, según Beinhauer, citado por Narbona, cuando «el hablante no encuentra de momento ningún objeto para la comparación, y la frase se queda sin concluir», lo cual queda reflejado por el tono en la pronunciación y los puntos suspensivos en lo gráfico, que, en opinión del último, no serían necesarios (1989: 93), pero muy habituales en Frívola:

-Nunca pensé que fueras tan...

- -iDilo!

-Tan sentimental. (50)

En el caso anterior, el interlocutor no parece percibir que falte algo en la frase; de hecho, su siguiente intervención no es una oración interrogativa demandando información nueva, sino una imperativa forzando al otro a que haga explícito lo que ambos tienen en mente.

Si bien, como se viene observando, las funciones informativas suelen ser una constante a la hora de articular las construcciones del lenguaje coloquial, y a pesar de que por tal motivo en un diálogo lo conocido suele ser lo antepuesto en las subordinadas, Narbona Jiménez (1989: 109) afirma que no se puede reducir todo a la dualidad tema/rema, sino que influyen también los valores estilísticos, que pueden estar en la base de frases como:

-Cuando te encontré a ti, todo cambió, James me pareció ridículo. (153)

frente a una posible construcción menos marcada y sin intención de jerarquizar la información. En este ejemplo se observa además que la última cláusula aparece unida sin ningún tipo de nexo, lo cual da lugar a un tipo de oraciones sobre el que, como ha señalado Narbona (1989: 85), no parece haber un acuerdo entre los lingüistas acerca de si incluirlas en la parataxis o la hipotaxis, pero en las que los hablantes no encuentran ninguna dificultad para obtener o proporcionar la información requerida:

-Ten calma, Rita, confía en que Joe no te ha olvidado. (137)

-Pues no es una mujer, querida amiga, es un hombre flamante, con largos bigotes y un cráneo al descubierto. (115)

Ese carácter «descuidado» de la lengua oral es el que permite ciertas «anomalías» en el ámbito de las relaciones sintácticas que hacen «que, por 
ejemplo, el valor de una conjunción aparezca a veces como 'neutralizado' o reorientado o liberado», según Narbona Jiménez (1989: 112-114), del poder coercitivo de la sintaxis. Así, en Frívola podemos encontrar cuando desligado de su valor temporal habitual desempeñando el de condicional en:

-Me has dicho que vuestros padres rechazan esa boda... ¡Tonterías! Cuando dos se aman y desean casarse, no existe fuerza humana que les haga desistir de su propósito. Por otra parte, tú, mi pequeña impulsiva, eres una mujer demasiado personal para limitarte a obedecer a tu padre, $\underline{\text { cuando }}$ sabes que no es justo. (67)

Y un para que, cuyo valor, más que de finalidad, hay que entenderlo como concesivo, puesto que se supera un obstáculo para admitir lo expuesto:

-Demasiado hermosa para que me contemplaran ojos tan cínicos como los suyos. (32)

Estos casos ponen de manifiesto la estrechez del marco de algunas categorías gramaticales para explicar ciertas peculiaridades del habla coloquial, en donde no siempre se da una simetría entre sintaxis y semántica, aunque «tales desajustes», según Narbona Jiménez (1990: 118), no sean exclusivos de la modalidad de uso, pero su carácter parcelado o fragmenta$d o^{4}$ sí que «favorece el empleo de estas 'falsas' coordinaciones, así como de otras estructuras, también con y, de mero carácter ilativo», del tipo:

-Eso no está bien, Rita. Me has prometido tu amor y no permitiré que se lo lleve otro hombre. (21)

-Algún día me darás tu corazón y yo lo despreciaré. (25)

-¿Por qué no te casas con él? Es un chico agradable y te hará feliz.

-¡Oh, papá, entonces serías injusto y yo sé que siempre has sido recto y caballeroso! (164)

En todas ellas hubiera bastado con sustituir el nexo «débil» por otro más «fuerte» para que la función gramatical y el significado léxico estuvieran más cercanos. Pero, aunque desconozcamos la motivación última de la autora para elegir uno en lugar de otro, el resultado final es que sirven para caracterizar la modalidad de uso frente a la escrita en muchos de los diálogos de la novela.

${ }^{4}$ Las comillas y las cursivas son de Narbona. 


\subsection{Otros rasgos caracterizadores de lo oral en la literatura}

Además de los recursos que se han venido analizando hasta aquí, otros elementos caracterizadores del lenguaje oral presentes en las intervenciones de los personajes de Frívola y de otras obras literarias son los que López Serena (2007: 105), en su propuesta de combinar el análisis de la reproducción de la llamada habla coloquial en la literatura, tanto con la estilística literaria, como la estilística de la lengua, denomina figuras de simetría, de enumeración y del paréntesis.

Las primeras, las figuras de simetría, ya sea mediante la repetición de materiales sintácticos o léxicos por parte de uno de los emisores, como por el concurso de ambos, bien en la misma disposición o de manera inversa en forma de quiasmo, sirven tanto para agilizar los diálogos con rápidas réplicas, como para acentuar la carga expresiva de lo dicho dándole un carácter sentencioso:

-¿Qué crueldad! -exclamó Ana.

-Eso digo yo: ¡qué crueldad! (12)

-... Ni tú vas a morirte por Arthur, ni él morirá por ti. Nadie muere por nadie. (13)

- $\underline{\text { Sucederá, lo sé porque tengo esa seguridad; pero lo cierto es que suce- }}$ derá. (66)

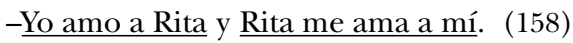

$-¿$ Entonces iremos los tres?

-Iremos los tres. (175).

-Ray y su esposa vivieron una vida desenfrenada; y como las mujeres de $\underline{\text { mis jefes antes, así la mujer de Ray, de fiesta en fiesta, de baile en baile, }}$ de unos brazos a otros... (17)

El ejemplo anterior, con repetición de materiales sintácticos y léxicos, sirve para introducir las figuras de enumeración, motivadas por el deseo de enfatizar lo que se dice o de desarrollar una idea mediante fórmulas sencillas de coordinación, uniendo a veces formas sintácticas incompletas:

-En tus sentidos estoy desde que me conociste, Smith. [...] Tú, me amarás, Joe, por encima de todo, de tu padre, del mío, de todos los rencores, y también por encima de mi frivolidad. ¡Me amarás apasionadamente! (33)

-... Mi verdadera felicidad estaba en los brazos, en los ojos y en el alma del hogar, que era mi querida Rita. Era como tú: bonita, frágil delicada... pero su carácter, muchacha, no tuvo punto de afinidad con el tuyo. (17) 
El apilamiento de la figura de acumulación puede estar relacionado con las rectificaciones que tienen lugar en las situaciones de habla coloquial, favorecidas por el carácter auditivo y la inmediatez comunicativa de esta, lo cual permite ir revisando las afirmaciones casi al mismo tiempo de haberlas formulado:

-Eso no lo sabe nadie, Rita. Yo creí... todos creíamos... que tú...

A veces, ello da lugar, también, a la figura del paréntesis, cuando un sintagma se coloca a manera de reflexión o comentario, con marcas de puntuación o no, en medio de otro al margen del tema principal:

-... De simple empleado pasé a ocupar el cargo de director, más tarde me dieron algunas acciones y al cabo de un buen puñado de años (ya estabas tú en el mundo, pues tu hermano muerto, nació doce meses antes que tú) ellos se retiraron y la fábrica pasó a mi poder. (17)

Lo que parecen evidenciar todos los ejemplos seleccionados es que la sintaxis oral, aun con ser más «libre», no es tan simple como pudiera pensarse, ni responde tampoco a la clasificación tradicional de los distintos tipos de oraciones que se han venido haciendo hasta ahora. En intervenciones como:

-Esas mujeres, Rita, fueron, una mi madre, muerta, y la otra, mi hermana. (50)

-Dime, Nati, necesito saber la verdad, toda la verdad. No omitas detalle. En ello va la felicidad de tu señorita y tú, Nati, siempre me has querido mucho (144),

se pueden encontrar prácticamente todas las figuras de la sintaxis coloquial mencionadas antes, pero resultan al mismo tiempo bastante elaboradas. Esto, incluso, lo vemos en la segunda de las dos intervenciones anteriores, aunque dé la impresión de que sintácticamente falta alguna marca o nexo que clarifique la relación que existe entre las distintas cláusulas o que pueda parecer incompleta. Sin embargo, su sentido semántico está bastante claro para el oyente, o, para ser más precisos, para el lector, que acepta la convención de hacer pasar un texto literario por una conversación coloquial, ya que lo de la calidad literaria va en gustos y cambia con las épocas.

\section{A MANERA DE RECAPITULACIÓN Y CONCLUSIONES}

Los ejemplos extraídos de los diálogos de Frívola muestran que, efectivamente, muchos de los rasgos propios de la oralidad se hallan presentes 
a lo largo de toda la novela. Es decir, los encuentros y los desencuentros de los personajes hacen que estos se interrumpan de forma continua entre ellos, que sus frases acaben solapándose y que se rectifiquen mutuamente en sus intervenciones. Esto hace que las conversaciones avancen con dificultad en algunos casos, pero también que se precipiten de manera vertiginosa en otros. Ahora bien, todos estos fenómenos propios de los intercambios orales, y algunos más, como las rupturas en el discurso de los personajes, las pausas, las reformulaciones y el predominio de la afectividad en sus expresiones, contribuyen de manera efectiva a caracterizar la personalidad de unos protagonistas que odian, aman, dudan, sufren, sienten remordimientos y se arrepienten.

En suma, los rasgos de oralidad en la novela ayudan a perfilar los rasgos psicológicos de unos personajes que, arrastrados por el torbellino de sus emociones, no encuentran el modo de expresarlos de manera ordenada y coherente. Esta incapacidad a la hora de comunicar sus sentimientos de una forma clara provoca un discurso plagado de repeticiones, de frases hechas, de refranes, de sobreentendidos y de oraciones inacabadas. Tales estados de exaltación y de hesitación tienen su reflejo lingüístico en un tipo de verbalizaciones con una sintaxis de tipo más suelta, lo que se traduce en una mayor abundancia de lo que aquí hemos llamado conectores débiles y en un predominio de la parataxis, ya que ambos recursos favorecen la transición libre de la conversación de unos temas a otros, adecuándose a los acontecimientos que suceden en ese mismo instante.

Sin embargo, la vinculación de los intercambios verbales de los protagonistas a su contexto inmediato no se traduce, como cabría esperar, en el uso de la deixis, que resulta más bien escasa a lo largo de la obra. Además, en el caso de aparecer, esta suele ir acompañada, ya sea por parte del narrador o de los propios interlocutores, por una referencia explícita a la realidad reemplazada por el deíctico.

De manera inversa, y contradiciendo, como en el caso de la escasez de deícticos, el principio de economía que rigen los intercambios orales, las innecesarias alusiones a un espacio y a un tiempo compartidos por los participantes de una conversación suponen que en los diálogos se aprecie una desviación de la modalidad oral de la lengua. Ello pone de manifiesto la existencia de un narrador atento, preocupado, no solo por reproducir el discurso oral en las intervenciones de sus personajes, sino por que la información que se quiere transmitir llegue de manera íntegra a los lectores de la novela y no solo a los implicados, que serían los protoganistas.

En resumen, después de todo lo expuesto hasta ahora, no parece que los rasgos de oralidad descritos en los diálogos de Frívola respondan a un mero trasvase de la lengua coloquial a la novela, achacable al buen oído de la autora para reproducir tanto las conversaciones de la calle, como las 
de los salones más elegantes. Por consiguiente, aun sin pretender hacer una valoración literaria de la obra, sería preciso admitir que la presencia de dichos rasgos son fruto de una serie de elecciones que pertenecen a la poética personal de Corín Tellado, en la cual consigue conjugar la estilística de la oralidad y de la literatura para transportar al lector al mundo de ficción de la novela rosa.

Dicho de otra manera, Corín Tellado, al incorporar ciertos rasgos de la oralidad a los diálogos de sus personajes, llega a lograr de sus lectores que acepten la existencia de una modalidad de habla que solo existe en un universo de fantasía creado por ella, en el que, precisamente, este uso particular de la lengua contribuye de manera eficiente a que los amantes de este género literario decidan tomar la realidad inventada de las novelas rosa, al menos mientras están sumergidos en su lectura, por cierta. 


\section{BIBLIOGRAFÍA}

Andreu, Alicia G. (2010): La construcción editorial de Corín Tellado, Vigo: Editorial Academia del Hispanismo.

BRUMME, Jenny y Hildegard RESINGER (2008): La oralidad fingida: obras literarias: descripción y traducción, vol. 2, Madrid: Iberoamericana Editorial.

Carmona González, Ángeles (2002): Corín Tellado. El erotismo rosa, Madrid: Espasa.

Casamiglia Blancafort, Helena y Amparo Tusón Valls (2002): Las cosas del decir, Barcelona: Ariel.

CASTAÑo Restrepo, Germán (2007): «Cultura popular, oralidad y literatura en Los funerales de la Mamá Grande», Anales de Literatura Hispanoamericana 36, 255-268.

CULLER, Jonathan (2000): Breve introducción a la teoría literaria, Barcelona: Crítica.

DANILOva, Oxana (2008): «El talk show: una entrevista particular», Boletín Hispánico Helvético 12, 139-152.

Eguidazu Palacios, Fernando (2008): Del folletín al bolsillo libro. 50 años de novela popular española (1900-1950), Guadalajara: Silente.

Illades Aguiar, Gustavo (2014): «La 'ecuación oralidad-escritura' en las letras hispánicas de los siglos XV-XVII (propuestas en torno a un diálogo en ciernes)», Criticón 120-121, 155-170. <https://journals.openedition.org/criticon/872>.

LÓPEz SERENA, Araceli (2007): Oralidad y escrituralidad en la recreación del español coloquial, Madrid: Gredos.

Matamala, Ana (2008): «La oralidad en la ficción televisiva: análisis de las interjecciones de un corpus de comedias de situación originales y dobladas». En Jenny Brume (ed.), La oralidad fingida: descripción y traducción. Teatro, cómic y medios audiovisuales, Madrid: Iberoamericana, 81-94.

NARBONA JIMÉNEZ, Antonio (1989): Las subordinadas adverbiales impropias en español (Bases para su estudio), Málaga: Librería Ágora.

- (1989b): Sintaxis española: nuevos y viejos enfoques, Barcelona: Ariel.

- (1990): Las subordinadas adverbiales impropias en español (II) (Bases para su estudio), Málaga: Librería Ágora.

- (2015): Sintaxis del español coloquial, Sevilla: Editorial Universidad de Sevilla.

NARO, Guilhem (2008): «Las marcas de oralidad en el cómic Iznogood y su traducción del francés al español». En Jenny Brume (ed.), La oralidad fingida: descripción y traducción. Teatro, cómic y medios audiovisuales, Madrid: Iberoamericana, 95-104.

Pérez Álvarez, Bernardo E. (2010): «Transformaciones estructurales entre el habla y la escritura». En Isabel Contreras Islas y Anna Dolores García Collino (eds.), Escritos sobre oralidad, México: Universidad Iberoamericana, 99-126.

RESINGER, Hildegard (2008): La oralidad fingida: descripción y traducción: teatro, cómic y medios audiovisuales (Vol. 1), Madrid: Iberoamericana Editorial. 
RuedA, Ana (2008): «La reformulación en el discurso periodístico: una muestra de oralidad fingida», Oralia 11, 353-374.

SACIDO Romero, Alberto (1995-97): «Oralidad, escritura y dialogismo en El Quijote de 1605», Anales Cervantinos xxxiII, 39-60. <http://analescervantinos. revistas.csic.es/index.php/analescervantinos/article/viewFile/302/303>.

SÁnchez BARBudo, Antonio (1957): «Vulgaridad y genio de Galdós. El estilo y la técnica de Miau», Archivum: Revista de la Facultad de Filología 7, 48-76.

Tejero Osuna, Macu (2012): Amapola, Madrid: Plaza y Janés.

Tellado, Corín (2004): Frívola, Barcelona: Martínez Roca.

- (2004): Angustiosa esclavitud, Barcelona: Martínez Roca.

TeLLER, Janne (2011): Nada, Barcelona: Seix Barral.

ViÑao Frago, Antonio (2004): «Oralidad y escritura en El Quijote: ¿ioposición o interacción?», Revista de educación. Número extraordinario, 27-47. <http:// www.mecd.gob.es/dctm/revista-de-educacion/articulosre2004/re200403.pdf? documentId=0901e72b812042a2>. 